Western University

Scholarship@Western

Department of Economics Research Reports

Economics Working Papers Archive

1971

\title{
Factor Market Distortions and the Two-Sector Model of Economic Growth
}

Raveendra Batra

Francisco R. Casas

Follow this and additional works at: https://ir.lib.uwo.ca/economicsresrpt

Part of the Economics Commons

Citation of this paper:

Batra, Raveendra, Francisco R. Casas. "Factor Market Distortions and the Two-Sector Model of Economic Growth." Department of Economics Research Reports, 7102. London, ON: Department of Economics, University of Western Ontario (1971). 
RESEARCH REPORT 7102

FACTOR MARKET DISTORTIONS AND THE

TWO-SECTOR MODEL OF ECONOMIC GROWTH

\author{
by \\ Raveendra Batra \\ and \\ Francisco R. Casas
}


FACTOR MARKET DISTORTIONS AND THE TWO-SECTOR MODEL

OF ECONOMIC GROWTH

The features of a two-sector, two-factor model of economic growth have been extensively analyzed by many economists in recent years. The popularity of this model with growth theorists can be gauged from the fact that after the pioneering work by Shinkai (1960) and Uzawa (1961), more than twenty related papers have been written in the last ten years. ${ }^{1}$ Indeed, in the words of Inada (1964, p. 127), "this is one of the most important contributions to the economic growth theories, and the structures of the model or equivalently the relationship between the assumptions and results in such an important work will be worth while to be studied in more detail."

Although the discovery of the two-sector growth model has been very interesting and fascinating, and has increased our comprehension of the growth behavior of the capitalistic economic system characterized by free market enterprise, yet the model is far from reality. One of the central assumptions of this model (and growth models in general) is that all markets are characterized by perfect competition which implies, among other things, that a11 factors of production receive the same reward in both sectors. Now in a world where the capitalist system permits and encourages the existence of "business" unionism in order to protect the rights of workers, the assumption of similar factor rewards in all sectors of production may be far from truth. Thus a perpetual inter-sectoral wage differential may be caused by different policies followed by trade unions in the two sectors. Bhagwati and Ramaswami (1963) have enumerated several other reasons for the existence of the wage differential. Furthermore, not only the wage rate but also the reward of capital may differ in the two sectors. For instance, Harberger (1962) has shown that a tax on the use of capital in one sector alone (the corporate 
sector) will drive a wedge between rewards of capital in the two sectors. Furthermore, this intersectoral factor-price differential is compatible with perfect factor mobility.

The purpose of this paper is to relax the assumption of perfect factor markets and explore the consequences of the introduction of intersectoral factor-price differentials for stability in the traditional two-sector model of economic growth. Some of the results that we derive appear to be intereting as well as unexpected. ${ }^{2}$ For example, a sufficient condition for stability in the traditional two-sector model is that the consumption goods sector be capital-intensive relative to the capital-goods sector. This condition is now well known as the capital-intensity condition. In the presence of the factor-price differential, however, the factor-intensity of the two sectors comes to acquire a special meaning and interpretation. A distinction has now to be drawn between the factor-intensity in the "physical" as well as in the "value" sense. Thus the traditional capital-intensity condition, which in our model turns out to be the comparison between two factor-intensities in the physical sense only, is no longer sufficient for stability in the economic system. Section I deals with the assumptions and other ingredients of the model, section II with the uniqueness of equilibrium at any moment of time, section III with the stability of the long run equilibrium for a given level of the factor-price differential, and section IV with the effects of a change in the degree of distortion. ${ }^{3}$ Finally the major findings of the paper are summarized in section $V$.

\section{Assumptions and the ModeI}

Except for the presence of an intersectoral factor-price differential, the assumptions of this paper are the same as those of the traditional twosector growth mode1. There are two sectors of production, the capital-goods 
sector (sector 1) and the consumption goods sector (sector 2), with the outputs in these sectors denoted by $\mathrm{y}_{1}$ and $\mathrm{y}_{2}$ respectively. There are two factors of production, capital (K) and labor (L); there is perfect competition in the product markets, but imperfect competition in the factor markets. Without loss of generality it is assumed that the reward of capital is the same in the two sectors, but the wage rates differ; returns to scale are constant but returns to factor proportions are diminishing; full employment, perfect factor mobility, a constant propensity to save, a constant rate of depreciation, and an exogenously given rate of growth of labor are also assumed.

The main tool of our analysis is the "activity-analysis" technique developed by Jones (1965) and later on utilized by Batra (1969).

The two production functions are:

$$
\mathrm{y}_{1}=\mathrm{F}_{1}\left(\mathrm{~L}_{1}, \mathrm{~K}_{1}\right)
$$

and

$$
\mathrm{y}_{2}=\mathrm{F}_{2}\left(\mathrm{~L}_{2}, \mathrm{~K}_{2}\right)
$$

With linearly homogeneous production functions the entire information concerning the production surface can be summed up in the unit isoquant which denotes an output of one unit. The two production functions can accordingly be expressed as

$$
F_{1}\left(L_{1} / y_{1}, K_{1} / y_{1}\right)=F_{1}\left(a_{L 1}, a_{K 1}\right)=1
$$

and

$$
\mathrm{F}_{2}\left(\mathrm{~L}_{2} / \mathrm{y}_{2}, \mathrm{~K}_{2} / \mathrm{y}_{2}\right)=\mathrm{F}_{2}\left(\mathrm{a}_{\mathrm{L} 2}, \mathrm{a}_{\mathrm{K} 2}\right)=1 \text {, }
$$

where $a_{i j}$ denotes the amount of the $i^{\text {th }}$ factor per unit of the $j^{\text {th }}$ product $(i=L, K ; j=1,2)$.

With full employment of both factors,

$$
a_{L 1} y_{1}+a_{L 2} y_{2}=\bar{L}
$$


and

$$
a_{\mathrm{K} 1} \mathrm{y}_{1}+a_{\mathrm{K} 2} \mathrm{y}_{2}=\dot{\overline{\mathrm{K}}}
$$

where the bars indicate that both factors are in inelastic supply at any moment of time. Under perfect competition in product markets, unit costs reflect product prices. Let $r$ stand for the reward of capital, $w_{j}$ for the wage rate and $p_{j}$ for the price in the two sectors. Then

$$
\mathrm{a}_{\mathrm{Ll}} \mathrm{w}_{1}+\mathrm{a}_{\mathrm{K} 1} \mathrm{r}=\mathrm{p}_{1}
$$

and

$$
a_{L 2} w_{2}+a_{K 2} r=p_{2} \text {, }
$$

where

$$
\alpha w_{1}=w_{2} \cdot \quad(\alpha \neq 1) .
$$

If production coefficients are fixed, equations (1.1) - (1.4) describe the production side of the system. However, in the general case of variable coefficients, four additional equations must be introduced in order to determine the four input-output coefficients $\left(a_{i j}\right.$ 's). These are provided by the requirement that with linearly homogeneous production functions, each $a_{i j}$ is determined solely by the factor-price ratio. Let $\omega_{j}=w_{j} / r$ be the wage/rental ratio in the $j^{\text {th }}$ sector. Then

$$
a_{i j}=a_{i j}\left(w_{j}\right)
$$

So far we have described the production side of the system. To close the model, we postulate the following demand specification:

$$
\text { (1.7) } \quad S=\text { sy }
$$

where $S$ equals savings, $s$ denotes the constant average propensity to save and $y$ the level of national income: 


$$
y=p_{1} y_{1}+p_{2} y_{2}
$$

Under the condition that savings equal investment in equilibrium, we may write,

$$
p_{1} y_{1}=s\left(p_{1} y_{1}+p_{2} y_{2}\right) \text {, or }
$$

$$
\frac{y_{1}}{y_{2}}=\frac{s}{1-s} \cdot \frac{p_{2}}{p_{1}}=c \frac{p_{2}}{p_{1}}
$$

where $c=s / 1-s$ is a constant. With this last equation, we have gathered the full complement of ingredients with which to conduct further analysis.

\section{Uniqueness of Momentary Equilibrium}

This section is concerned with the derivation of certain conditions which will ensure the existence and uniqueness of equilibrium at any moment of time, where the supply of labor and capital are given. It is evident from equation (1.6) that the input coefficients are uniquely determined once $w_{j}$ is known, and with $a_{i j}$ so determined, the rest of the variables can be easily determined from other equations presented in the last section. Thus the important point is to obtain a relationship between the overall capital/ labor ratio $(K / L=k)$ and $\omega_{j}$ and, furthermore, to derive conditions that will ensure that $\omega_{j}$ is uniquely determined from the $k$ which is given at any moment of time. In order to obtain this relationship the system of equations presented in the last section must be converted into equations of change. Let an asterisk indicate the relative change in a variable or parameters $(\overline{\mathrm{L}}, \overline{\mathrm{K}}$, $\mathrm{p}_{1}$ and $\mathrm{p}_{2}$ ). Thus $\mathrm{y}_{1}^{*}=d \mathrm{y}_{1} / \mathrm{y}_{1}$, etc. Differentiating equations (1.1) - (1.5), we obtain:

$$
\lambda_{L 1} \mathrm{y}_{1}^{*}+\lambda_{L 2} \mathrm{y}_{2}^{*}=L^{*}-\left(\lambda_{L 1} \mathrm{a}_{\mathrm{L} 1}^{*}+\lambda_{L 2}{ }^{a_{L 2}^{*}}\right)
$$




$$
\begin{aligned}
& \lambda_{\mathrm{K} 1} \mathrm{y}_{1}^{*}+\lambda_{\mathrm{K} 2} \mathrm{y}_{2}^{*}=\mathrm{K}^{*}-\left(\lambda_{\mathrm{K} 1} \mathrm{a}_{\mathrm{K} 1}^{*}+\lambda_{\mathrm{K} 2} \mathrm{a}_{\mathrm{K} 2}^{*}\right) \\
& \theta_{\mathrm{L} 1} \mathrm{w}_{1}^{*}+\theta_{\mathrm{K} 1} \mathrm{r}^{*}=\mathrm{p}_{1}^{*}-\left(\theta_{\mathrm{L} 1} \mathrm{a}_{\mathrm{L} 1}^{*}+\theta_{\mathrm{K} 1} \mathrm{a}_{\mathrm{K} 1}^{*}\right) \\
& \theta_{\mathrm{L} 2^{\mathrm{w} 2}}+\theta_{\mathrm{K} 2} \mathrm{r}^{*}=\mathrm{p}_{2}^{*}-\left(\theta_{\mathrm{L} 2^{\mathrm{a}_{\mathrm{L} 2}}}+\theta_{\mathrm{K} 2^{a_{\mathrm{K} 2}}}\right), \text { and } \\
& \alpha^{*}+\mathrm{w}_{1}^{*}=\mathrm{w}_{2}^{*} .
\end{aligned}
$$

In equations (2.1) - (2.4), $\lambda_{L j}=a_{L j} X_{j} / L$ and $\lambda_{K j}=a_{K j} X_{j} / K$, whereas $\theta_{L j}=a_{L j} w_{j} / p_{j}$ and $\theta_{K j}=a_{K j} r / p_{j}$. In other words, $\lambda_{i j}$ is the fraction of the $i$ th factor employed in the $j$ th sector, whereas $\theta_{i j}$ is the distributive share of the $i^{\text {th }}$ factor in the total earnings of the $j^{\text {th }}$ sector. By their definition, $\lambda_{i 1}+\lambda_{i 2}=1$ and $\hat{q}_{\mathrm{j}}+\theta_{\mathrm{kj}}=1$. Let $\lambda$ and $\theta$ denote the matrices of coefficients shown in (2.1) - (2.4). Then
$\lambda=\begin{array}{ll}\lambda_{\mathrm{L} 1} & \lambda_{\mathrm{L} 2} \\ \lambda_{\mathrm{K} 1} & \lambda_{\mathrm{K} 2}\end{array} ;$

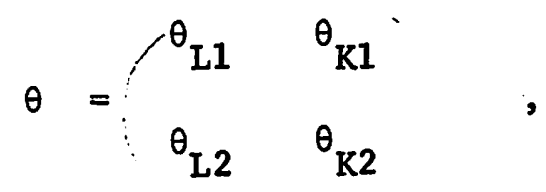

where the determinants of $\lambda$ and $\theta$ are given by

$$
\begin{aligned}
|\lambda| & =\frac{y_{1} y_{2}}{L K}\left(a_{L 1} a_{K 2}-a_{L 2} a_{K 1}\right) \\
& =\frac{y_{1} y_{2}}{L K} \cdot a_{L 1} a_{L 2}\left(k_{2}-k_{1}\right), \text { and } \\
|\theta| & =\frac{1}{p_{1} p_{2}}\left(w_{1} a_{L 1} \cdot r a_{K 2}-w_{2} a_{L 2} \cdot r a_{K 1}\right) \\
& =\frac{w_{1} r}{p_{1} p_{2}} a_{L 1} a_{L 2}\left(k_{2}-\alpha k_{1}\right),
\end{aligned}
$$

where $k_{j}=k_{j} / L_{j}$ is the capital/labor ratio in the $j^{\text {th }}$ sector. Since each row sum in the $\lambda$ and $\theta$ matrices add to unity, $|\lambda|$ and $|\theta|$ can also be written as: 
$(2.6 *)$

$$
|\lambda|=\lambda_{L 1}-\lambda_{K 1}=\lambda_{K 2}-\lambda_{L 2}
$$

$|\theta|=\theta_{\mathrm{L} 1}-\theta_{\mathrm{L} 2}=\theta_{\mathrm{K} 2}-\theta_{\mathrm{K} 1}$

With perfect competition in the product markets,average revenue equals unit cost in each sector, which equals $\left(a_{L_{j}}{ }^{w}{ }_{j}+a_{K j} r\right)$. Each producer treats factor prices as fixed and chooses such factor combinations as minimize the unit cost, which implies that the first derivative of $\left(a_{L j} w_{j}+a_{K j} r\right)$ should be zero. That is,

$$
\begin{aligned}
& \theta_{L 1} a_{L 1}^{*}+\theta_{K 1} a_{K 1}^{*}=0, \text { and } \\
& \theta_{L 2} a_{L 2}^{*}+\theta_{K 2} a_{K 2}^{*}=0 .
\end{aligned}
$$

Substituting these in (2.3) and (2.4) yields:

$$
\begin{aligned}
& \theta_{\mathrm{L} 1} \mathrm{w}_{1}^{*}+\theta_{\mathrm{K} 1} \mathrm{r}^{*}=\mathrm{p}_{1}^{*} \\
& \theta_{\mathrm{L} 2^{\mathrm{w}} 1}+\theta_{\mathrm{K} 2} \mathrm{r}^{*}=\mathrm{p}_{2}^{*}-\alpha^{*} \theta_{\mathrm{L} 2} .
\end{aligned}
$$

Next equations (2.1) and (2.2) should be simplified. Let $\sigma_{j}$ be the elasticity of factor substitution in the $j^{\text {th }}$ sector. Then $\sigma_{j}$ is defined as:

$$
\sigma_{1}=\frac{a_{K 1}^{*}-a_{L 1}^{*}}{w_{1}^{*}-r^{*}} \text {, and }
$$

$$
\sigma_{2}=\frac{a_{\mathrm{K} 2}^{*}-a_{L 2}^{*}}{r_{2}^{*}-r^{*}}
$$

These together with (2.5), (2.7) and (2.8) yield the following equations:

$$
\begin{aligned}
& a_{L 1}^{*}=-\theta_{K 1} \sigma_{1}\left(w_{1}^{*}-r^{*}\right) \\
& a_{K 1}^{*}=\theta_{L 1} \sigma_{1}\left(w_{1}^{*}-r^{*}\right)
\end{aligned}
$$

$$
a_{L 2}^{*}=-\left[\theta_{K 2} \sigma_{2}\left(w_{1}^{*}-r^{*}\right)+\theta_{K 2} \sigma_{2} \alpha^{*}\right]
$$




$$
a_{\mathrm{K} 2}^{*}=\theta_{L 2} \sigma_{2}\left(w_{1}^{*}-r^{*}\right)+\theta_{L 2} \sigma_{2} \alpha^{*}
$$

Substituting these equations in (2.1) and (2.2), and utilizing (2.5) we obtain:

$$
\begin{aligned}
& \lambda_{\mathrm{L} 1} \mathrm{y}_{1}^{*}+\lambda_{\mathrm{L} 2} \mathrm{y}_{2}^{*}=\mathrm{L}^{*}+\beta_{\mathrm{L}}\left(\mathrm{w}_{1}^{*}-\mathrm{r}^{*}\right)+\lambda_{\mathrm{L} 2}{ }_{\mathrm{K} 2} \sigma_{2} \alpha^{*} \\
& \lambda_{\mathrm{K} 1} \mathrm{y}_{1}^{*}+\lambda_{\mathrm{K} 2} \mathrm{y}_{2}^{*}=\mathrm{K}^{*}-\beta_{\mathrm{K}}\left(\mathrm{w}_{1}^{*}-\mathrm{r}^{*}\right)-\lambda_{\mathrm{K} 2} \theta_{\mathrm{L} 2} \sigma_{2} \alpha^{*}
\end{aligned}
$$

where $\beta_{L}=\lambda_{L 1} \theta_{K 1} \sigma_{1}+\lambda_{L 2} \theta_{K 2} \sigma_{2}>0$, and

$$
\beta_{\mathrm{K}}=\lambda_{\mathrm{K} 1}{ }_{\mathrm{L} 1} \sigma_{1}+\lambda_{\mathrm{K} 2}{ }^{{ }_{\mathrm{L} 2} \sigma_{2}}>0
$$

Assume for the time being, that the wage differential is constant so that $\alpha^{*}=0$. Later on we shall relax this assumption and see how our results are modified. With $\alpha^{*}=0,(2.17)$ and $(2.18)$ can be solved to yield:

$$
\mathrm{y}_{1}^{*}-\mathrm{y}_{2}^{*}=\frac{\mathrm{L}^{*}-\mathrm{K}^{*}}{|\lambda|}+\frac{\left(\beta_{\mathrm{L}}+\beta_{\mathrm{K}}\right)\left(\mathrm{w}_{1}^{*}-\mathrm{r}^{*}\right)}{|\lambda|}
$$

From equation (1.9) we get:

$$
\mathrm{y}_{1}^{*}-\mathrm{y}_{2}^{*}=\mathrm{p}_{2}^{*}-\mathrm{p}_{1}^{*}
$$

and from (2.9) and (2.10)

$$
p_{2}^{*}-p_{1}^{*}=-\left(w_{1}^{*}-r^{*}\right)|\theta|,
$$

remembering that with $\alpha^{*}=0, w_{1}^{*}=w_{2}^{*}$ from (2.5).

Equations (2.19) - (2.21) may now be solved to furnish: $w_{1}^{*}-r^{*}=\left(K^{*}-L^{*}\right) /$ $\left[\left(1+\sigma_{s}\right)|\lambda| \cdot|\theta|\right]$, or

$$
\omega_{1}^{*}=\frac{k^{*}}{\left(1+\sigma_{s}\right)|\lambda| \cdot|\theta|}=\frac{k^{*}}{\sigma}
$$

where $w_{1}^{*}=w_{1}^{*}-r^{*}, k^{*}=k^{*}-L^{*}$, and $\sigma_{s}=\frac{y_{1}^{*}-y_{2}^{*}}{p_{1}^{*}-p_{2}^{*}}=\frac{\beta_{L}+\beta_{\mathrm{K}}}{|\lambda| \cdot|\theta|}$ is the elasticity of substitution along the transformation curve, ${ }^{4}$ and 
$\sigma=\frac{\mathrm{k}^{*}}{\omega_{1}^{*}}=\left(1+\sigma_{\mathrm{s}}\right)|\lambda| \cdot|\theta|$ is the aggregate elasticity of substitution, i.e., the elasticity of the overall capital/labor ratio with respect to the wage/ rental ratio in any sector, for $k^{*} / w_{1}^{*}=k^{*} / w_{2}^{*}$ when $\alpha^{*}=0$. Equation

(2.2) furnishes the long sought after relationship between the overall capital/labor ratio and the wage/rental ratio in the two sectors. 5 However, before we proceed to analyze the relationship between $k$ and $w_{1}$, a few remarks concerning the signs of $|\lambda|,|\theta|$ and $\sigma_{s}$ are in order. It is at this stage that a distinction must be drawn between the factor-intensities in the physical and the value sense. The sign of $|\lambda|$ furnishes the relationship between factor-intensities in the two-sector in the physical sense, because here only the ratios between physical units of the factors employed in the two sectors are being compared. The sign of $|\theta|$ on the other hand describes the intersectoral factor-intensity relationship in the value sense, because here we compare the ratios between the value of factors employed in the two sectors. For example, $\left(k_{2}-\alpha k_{1}\right)$, which determines the sign of $|\theta|$ in $(2.5)$, is given by:

$$
\mathrm{k}_{2}-\alpha \mathrm{k}_{1}=\left(\mathrm{rk}_{2} / \mathrm{w}_{2} \mathrm{~L}_{2}\right)-\left(\mathrm{rk}_{1} / \mathrm{w}_{1} \mathrm{~L}_{1}\right)
$$

In the absence of the wage differential when $\alpha=1$, the signs of $|\lambda|$ and $|\theta|$ are the same, so that

$$
|\lambda| \cdot|\theta|>0
$$

However, in the presence of the wage differential $(\alpha \neq 1)$, the signs of $|\lambda|$ and $|\theta|$ may be different. For the sake of illustration, suppose that $k_{2}>k_{1}$, that is, the consumption-goods sector is capital-intensive relative to the capital-goods sector in the physical sense. Then $k_{2}>\alpha k_{1}$ if $\alpha<1$, which implies that $w_{1}>w_{2}$, so that the wage differential is paid by the producers 
in the capital-goods sector, which is labor-intensive relative to the consumption-goods sector. In other words, the differential is paid by the first sector on its intensive factor. Thus we conclude that $|\lambda|$ and $|\theta|$ have the same sign if the differential is paid by a sector for its intensive factor. However, if a sector pays the differential on its nonintensive factor, the story is different. Here $|\lambda|$ and $|\theta|$ may have different signs, because $\alpha>1$. In other words, a sector may be intensive in the use of one factor in the physical sense but unintensive in the use of the same factor in the value sense.

The picture is further blurred by the fact that, as demonstrated by Johnson (1966), the physical factor-intensity relationships may also change sign in the presence of the wage differential, even though in its absence, they are nonreversible.

A11 this leads us to the conclusion that the existence of the wage differential may cause reversals in the factor-intensity relationships between the two sectors in the physical sense and/or in the value sense. 6

The complications caused by the wage differential do not end here. Bhagwati and Srinivasan (1971) and Kemp and Herberg (1969) have recently shown that outputs may respond "perversely" to changes in commodity prices. By this they mean that the output of a commodity may actually decline as a result of a rise in its relative price and vice versa. Specifically, this may occur if the factor-intensities get reversed either in the physical sense or in the value sense. Thus in the presence of the wage differential, $\sigma_{s}$ which is positive in its absence, may actually be negative. Symbolically, 
$\sigma_{s} \gtrless 0$, if $|\lambda| \cdot|\theta| \gtrless 0$. Hereafter, we assume that $\sigma_{s} \neq-1$, because, as is evident from $(2.22)$, the system becomes indeterminate if $\sigma_{s}=-1$.

With these remarks in mind, we now proceed to derive sufficient conditions which will ensure a unique relationship between $k$ and $\omega_{1}$ and, thereby, the unique determination of all variables in the system. It can be easily shown that the capital/labor ratio in each sector is positively related to its wage/rental ratio because of our homogeneity assumption for

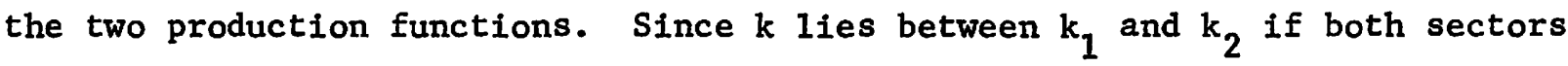
are to produce positive outputs, one would expect a positive relationship between $k$ and the wage/rental ratio in the two sectors. Thus for the viability of the economic system, the relationship between $k$ and $w_{1}$, apart from being unique, should be positive, or $\omega_{1}^{*} / k^{*}>0$.

A careful examination of $(2.22)$ reveals that $\omega_{1}^{*} / k^{*}>0$ if $|\lambda|$ and $|\theta|$ have the same sign. Because here not only $|\lambda| \cdot|\theta|>0$, but $\sigma_{s}$ is also positive. This means that the physical and the value factor-intensities either never get reversed, or both get reversed at the same time. However, if only the physical or the value factor-intensities get reversed for some $\omega_{1}, \omega_{1}^{*} / k^{*}$ may possess any sign, thereby generating the possibility of multiple equilibria. ${ }^{7}$ of course, here also $\omega_{1}^{*} / k^{*}$ is positive if $\left|\sigma_{s}\right|>1$.

These results will perhaps gain further clarification with the help of diagrams. Consider Figure 1 which depicts a monotonic and positive relationship between $k, w_{1}$ and $w_{2}$. Once the relationship between $k$ and $w_{1}$ is determined, the relationship between $k$ and $\omega_{2}$ is automatically determined by the fact that $\alpha_{1}=w_{2}$, where $\alpha$ is a given constant. Suppose at any moment of time, $k$ is given by $\bar{k}$, then $\omega_{1}$ is given by $\bar{w}_{1}$ and the level of $\omega_{2}$ can be appropriately determined depending on whether $\alpha$ is less or greater than one. 


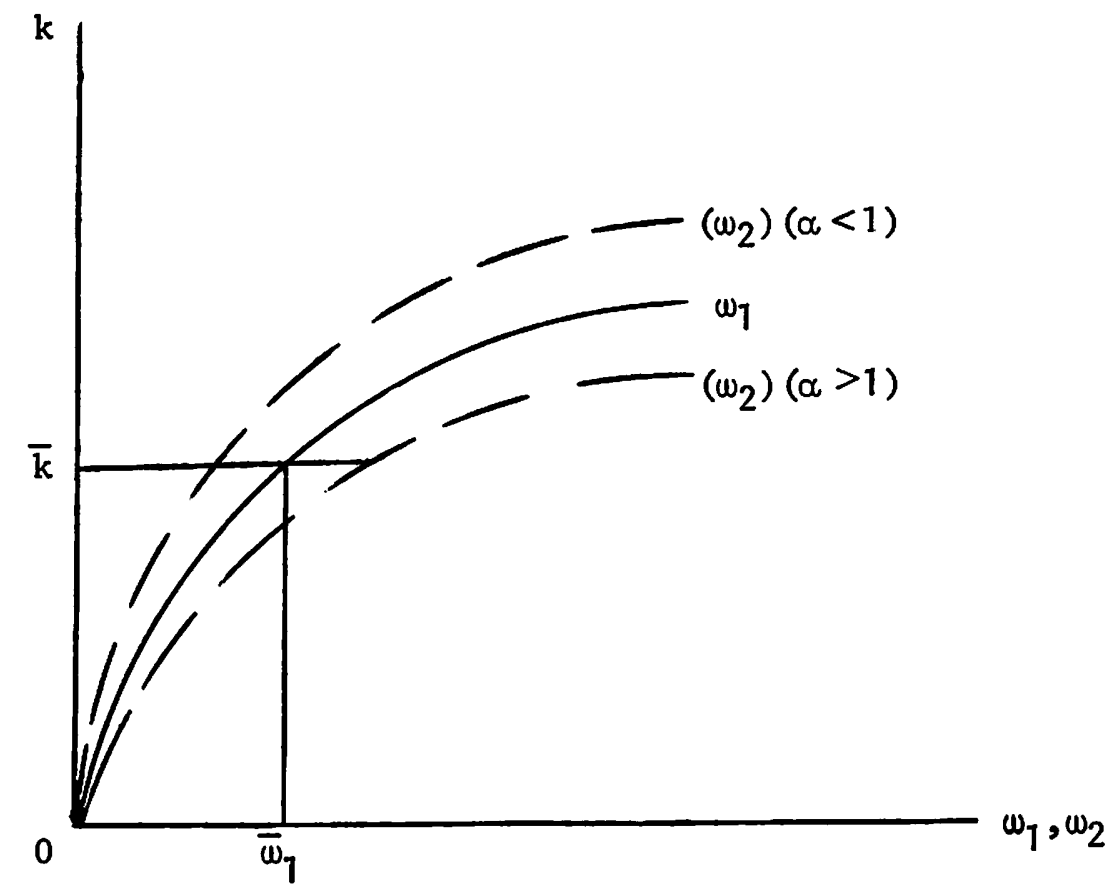

Figure 1

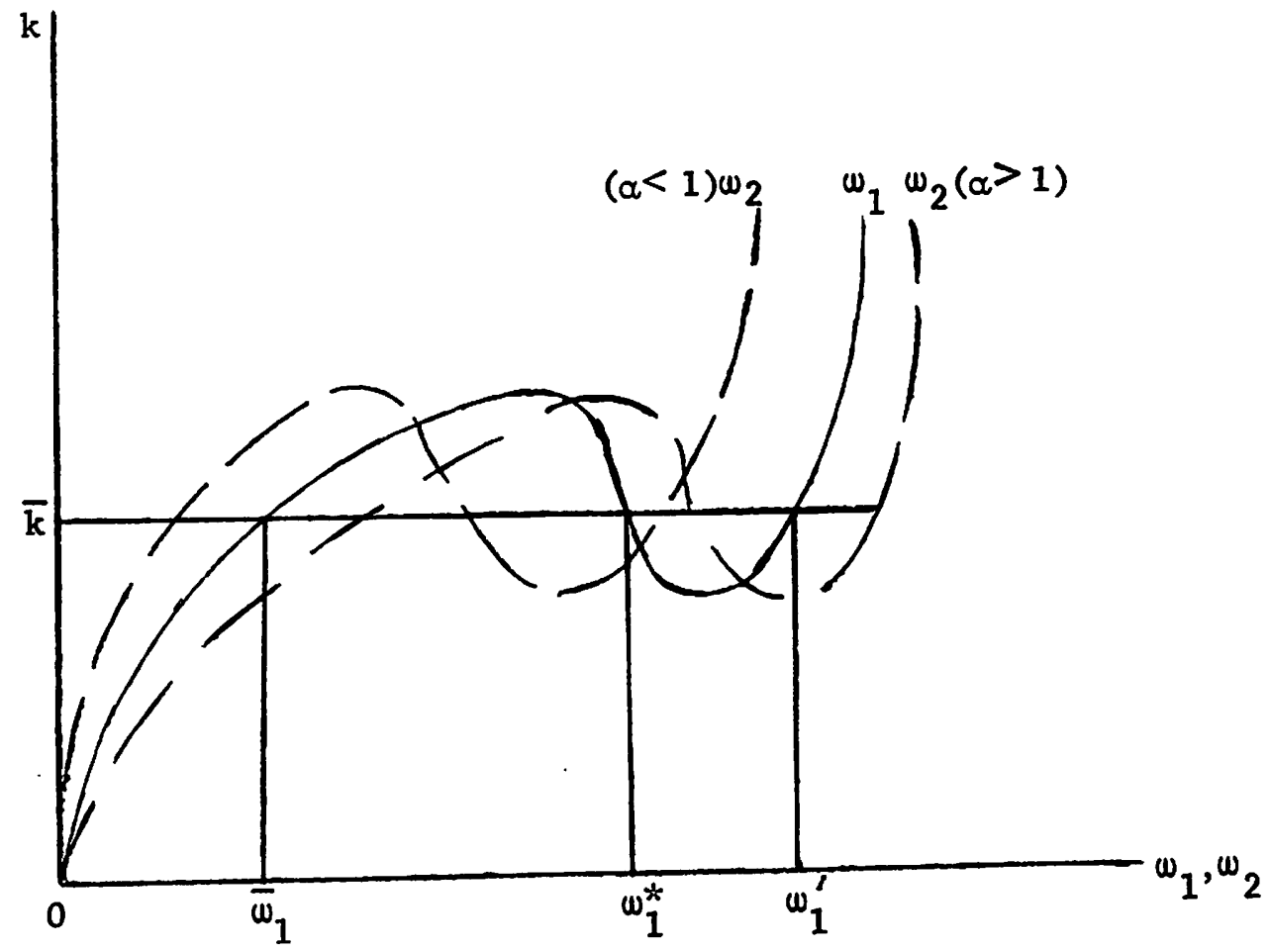

Figure 2 
Once $w_{j}$ is determined, the rest of the variables can be easily determined. The story, however, is different in Figure 2. Here the relationship between $k$ and $\omega_{1}$ (or $\omega_{2}$ ) is no longer monotonic. As can be seen for any $k$ equal to $\bar{k}$, there are three equilibrium values of $\omega_{1}\left(\bar{w}_{1}, w_{1}^{*}\right.$ and $\left.w_{1}^{\prime}\right)$ and hence three equilibrium values for $\omega_{2}$. Thus Figure 2 shows the possibility of multiple equilibria.

It is interesting to note here that in the absence of the wage differential, the momentary equilibrium is always uniquely determined. For here $|\lambda|$ and $|\theta|$ always have the same sign and $\sigma_{s}>0$.

III. Existence and Stability of the Long Run Equilibrium

The long run growth path of an economy is determined by the rate of capital accumulation and the exogenously determined rate of growth of labor $\left(L^{*}\right)$. A growth model is said to be stable if the rate of growth of capital, if not initially equal to the given rate of growth of labor, always converges to $\mathrm{L}^{*}$. In other words, if the capital stock is growing faster (slower) than labor, the rate of growth of capital declines (rises) and, in the limit, equals the given rate of growth of labor. The growth path where capital and labor grow at the same rate is called the balanced growth path. Symbolically, the attainment of the balanced growth path requires that $\mathrm{dK}^{*} / \mathrm{dk}<0$. Now $\mathrm{R}^{*}$, with savings equal to investment, is given by $y_{1} / K$. Let $\left(y_{1} / k\right)=\phi$. Thus, for the stability and uniqueness of the long run equilibrium,

$$
\frac{\mathrm{y}_{1}^{*}-\mathrm{K}^{*}}{\mathrm{~K}^{*}-\mathrm{L}^{*}}=\frac{\phi^{*}}{\mathrm{k}^{*}}<0 \text {. }
$$

$\mathrm{y}_{1}^{*}$ can be obtained from (2.17) and (2.18). Remembering that $\alpha^{*}=0$, we derive:

$$
\mathrm{y}_{1}^{*}=\frac{\lambda_{\mathrm{K} 2}\left[\mathrm{~L}^{*}+\beta_{\mathrm{L}}\left(\mathrm{w}_{1}^{*}-\mathrm{r}^{*}\right)\right]-\lambda_{\mathrm{L} 2}\left[\mathrm{~K}^{*}-\beta_{\mathrm{K}}\left(\mathrm{w}_{1}^{*}-\mathrm{r}^{*}\right)\right]}{|\lambda|}
$$


Adding $-\mathrm{K}^{*}$ to both sides of $(3.1)$ and using (2.22), we obtain:

( 3.2) $\frac{\mathrm{y}_{1}^{*}-\mathrm{K}^{*}}{\mathrm{~K}^{*}-\mathrm{L}^{*}}=\frac{\phi^{*}}{\mathrm{k}^{*}}=\frac{-\left(\beta_{\mathrm{K}}+\lambda_{\mathrm{K} 2}|\theta|\right)}{\left(1+\sigma_{\mathrm{s}}\right)|\lambda| \cdot|\theta|}$,

where, as before, $\beta_{\mathrm{K}}=\lambda_{\mathrm{K} 1} \theta_{\mathrm{L} 1} \sigma_{1}+\lambda_{\mathrm{K} 2} \theta_{\mathrm{L} 2} \sigma_{2}>0$.

\section{A. The Capita1-Intensity Condition:}

Consider first the case where there is no wage differential $(\alpha=1)$. Here $|\lambda| \cdot|\theta|>0$ and $\sigma_{\mathrm{s}}$ is also positive. Since $\beta_{\mathrm{K}}>0, \phi^{*} / \mathrm{k}^{*}<0$ if $|\theta|>0$, which from (2.6) requires that $k_{2}>k_{1}$. This is, of course, the familiar capital-intensity condition.

Now consider the case where $\alpha \neq 1$. It is clear that even if $k_{2}>k_{1}$, so that $|\lambda|>0$, there is no guarantee that $\phi^{*} / \mathrm{k}^{*}<0$. For one thing, the signs of $|\lambda|$ and $|\theta|$, as argued before, may be different, which gives rise to the additional complication that $\sigma_{s}<0$; for another, even if $|\lambda|$ and $|\theta|$ always have the same sign and hence $\sigma_{s}>0$, stability and uniqueness of the balanced growth pathare still far from assured, because of the unpredictable sign of $|\theta|$ which influences the sign of the numerator in (3.2). From this discussion we may conclude that even if the capital-intensity condition is satisfied, the two-sector growth model in the presence of an intersectoral wage differential may be unstable. Furthermore this possibility of instability does not derive from the multiplicity of momentary equilibria. Assume, for the moment, that the momentary equilibrium is always uniquely determined, so that the denominator of $(3.2)$ is positive. ${ }^{8}$ Now this denominator is positive under a variety of conditions. Consider, for example, the case where $|\lambda|>0$, so that the capital-intensity condition is satisfied, $|\theta|<0$, and $\left|\sigma_{s}\right|>1$. Here the denominator of (3.2) is positive, but the numerator will also be 
positive if $\left(\beta_{\mathrm{K}}+\lambda_{\mathrm{K} 2}|\theta|\right)<0$. Hence the economic system may be unstable in spite of the validity of the capital-intensity condition, even if the momentary equilibrium is uniquely determined. In light of this discussion, we may restate the capital-intensity condition and derive the following theorem:

Theorem 1: In the presence of intersectoral factor-price differential, a sufficient condition for the two-sector growth model to be stable is that the consumption-goods sector is capital-intensive relative to the capitalgoods sector in both the physical and the value sense.

\section{B. The Elasticity Condition:}

In the general case where the capital-intensity condition is not satisfied, the traditional two-sector growth model has been shown to be stable only if certain restrictions on the elasticity of factor substitution in the two sectors hold. This has now come to be known as the elasticity of substitution condition, or simply the elasticity condition. The relevance and significance of this condition will become apparent if we substitute the value of $\beta_{\mathrm{K}}$ in $(3.2)$ to obtain:

$$
\frac{\phi^{*}}{\mathrm{k}^{*}}=\frac{-\left[\lambda_{\mathrm{K} 1} \theta_{\mathrm{L} 1}\left(\sigma_{1}-1\right)+\lambda_{\mathrm{K} 2} \theta_{\mathrm{L} 2}\left(\sigma_{2}-1\right)+\theta_{\mathrm{L} 1}\right]}{\left(1+\sigma_{\mathrm{s}}\right)|\lambda| \cdot|\theta|}
$$

Evidently, a sufficient condition for $\phi^{*} / \mathrm{k}^{*}<0$ in the absence of the wage differential is that $\sigma_{j} \geq 1 \quad(j=1,2)$.

It is not difficult to see that $\sigma_{j} \geq 1$ is the elasticity condition in the traditional model when the propensity to save is assumed to be constant. In the presence of the wage differential, however, this condition must be supplemented by additional qualifications. The following theorem is immediate: 
Theorem 2: If the momentary equilibrium is uniquely determined, the two-sector growth model is stable in the presence of the wage differential, provided the elasticity of substitution in each sector is at least equal to one.

This is, of course, the traditional elasticity condition in a new guise. In the absence of the wage differential, the momentary equilibrium, as shown in the last section, is always uniquely determined when the propensity to save is constant. Hence the proviso attached to the elasticity condition in theorem 2 is not needed. This, however, is not true when a wage differential exists between the two sectors, because here the denominator of (3.3) may possess any sign. Thus, even if the traditional elasticity condition is satisfied, the economic system may be unstable in the presence of the wage differential.

of greater interest, however, is the case where the long run equilibrium may be uniquely determined, but the momentary equilibrium may not. This case never arises in the traditional two-sector growth models, because there the conditions for the stability and uniqueness of the long run equilibrium are invariably more stringent than those sufficient for the uniqueness of momentary equilibrium. That this may no longer be true in the presence of the wage differential, however, can be seen from (3.3). As stated earlier, the momentary equilibrium is not unique if for some $\omega_{1}$, the denominator of (3.3) is negative. However, this does not prevent $\phi^{*} / \mathrm{k}^{*}$ from being negative, provided the elasticity of substitution in one or both sectors is less than one, because for small values of $\sigma_{1}$ and/or $\sigma_{2}$, the numerator of ( 3.3 ) may be positive. 
C. Properties of the Balanced Growth Path:

Until now we have derived theorems which ensure the attainment, uniqueness and stability of the balanced growth path where both capital stock and labor force grow at the same constant rate. Although the stability theorems turn out to be substantially different from those in the traditional model, the properties of the balanced growth path essentially remain the same in spite of the wage differential. With $K^{*}=L^{*}$, it can be shown that all factor rewards and commodity prices remain constant. From (2.22), $\omega_{1}^{*}=0$ when $k^{*}\left(=K^{*}-L^{*}\right)=0$, which implies that input/output coefficients and hence factor rewards and from (1.3) and (1.4) commodity prices remain constant over time. In the balanced growth path, both sectors grow at the same rate as capital (or labor). For example, from ( 3.1$)$, with $\mathrm{K}^{*}=\mathrm{I}^{*}$ and $w_{1}^{*}-r^{*}=0, y_{1}^{*}$ can be written as

$$
\mathrm{y}_{1}^{*}=\mathrm{k}^{*} \frac{\left.\lambda_{\mathrm{K} 2}-\lambda_{\mathrm{L} 2}\right)}{|\lambda|}=\mathrm{K}^{*} \text {, }
$$

because from the fact that each row in the $\lambda$ matrix sums up to unity, $|\lambda|$ also equals $\left(\lambda_{\mathrm{K} 2}-\lambda_{\mathrm{L} 2}\right)$. Similarly, $\mathrm{y}_{2}^{*}$ can be shown to equal $\mathrm{K}^{*}$ or $\mathrm{L}^{*}$. Furthermore, national income also grows at the same rate. From (1.8) we obtain:

$$
y^{*}=A\left(p_{1}^{*}+y_{1}^{*}\right)+(1-A)\left(p_{2}^{*}+y_{2}^{*}\right) \text {, where } A=p_{1} y_{1} / y \text {. }
$$

Since $p_{1}^{*}=p_{2}^{*}=0, y^{*}=y_{2}^{*}$. Since national income grows at the same rate as labor and capital in the balanced growth path, it follows that the per capita income, the income/capital ratio and the per capita consumption in terms of $\mathrm{y}_{2}$ remain constant over time, that is, $\mathrm{y}^{*}-\mathrm{K}^{*}=\mathrm{y}^{*}-\mathrm{L}^{*}=\mathrm{y}_{2}^{*}-\mathrm{L}^{*}=0$. It may be observed that all these properties belong to the balanced growth path even when the wage differential does not exist. 


\section{IV - Comparative Dynamics}

The analysis so far has been conducted under the assumption that the wage differential remains constant throughout the growth process, so that $\alpha^{*}=0$. The discussion in the previous section was concerned with the derivation of conditions sufficient to ensure the uniqueness and the stability of the long run equilibrium, and we have seen that the balanced growth path may be uniquely determined for any given $\alpha$. This section is concerned with simple exercises in comparative dynamics. Given that the system has approached the balanced growth path, so that $k$ is constant over time, what happens if there is an exogenous change in $\alpha$, the degree of distortion? Specifically, we wish to determine the effects of a change in $\alpha$ on some key variables in the economic system at any given capital/1abor ratio (k). Although the balanced growth path is compatible with any $\alpha$ the balanced growth values of variables in the system will be different for different values of $\alpha$. Here and elsewhere we assume that the long run equilibrium is uniquely determined.

It is perhaps worth pointing out that the effects of a change in $\alpha$ have been explored by other authors, but only under the static framework, so that their analyses are essentially comparative-statics in nature.

First, we determine the effect of a change in $\alpha$ on the rate of growth of capital $(\phi)$. Unfortunately, the algebra here is more complicated. Therefore, only the key equations are presented in the text, their derivation being relegated to the appendix. Following essentially the same procedure as in section II, remembering that $\mathrm{K}^{*}=\mathrm{L}^{*}$ in the balanced growth path, we obtain the following equations: 


$$
w_{1}^{*}-p_{1}^{*}=\frac{\theta_{K 1}\left(|\lambda| \theta_{L 2}-A_{2} \sigma_{2}\right) \alpha^{*}}{\sigma}
$$

$$
w_{1}^{*}-p_{2}^{*}=\frac{\left(|\lambda| \theta_{K 1} \theta_{L 2}-\theta_{L 2} A_{1} \sigma_{1}-A_{2} \sigma_{2}\right) \alpha^{*}}{\sigma}
$$

$$
w_{2}^{*}-p_{1}^{*}=\frac{\left(|\lambda| \theta_{K 2} \theta_{L 1}+A_{1} \sigma_{1}+\theta_{L 1} A_{2} \sigma_{2}\right) \alpha^{*}}{\sigma}
$$

$$
w_{2}^{*}-p_{2}^{*}=\frac{\theta_{\mathrm{K} 2}\left(|\lambda| \theta_{\mathrm{L} 1}+A_{1} \sigma_{1}\right) \alpha^{*}}{\sigma}
$$

$$
r^{*}-p_{1}^{*}=\frac{-\theta_{L 1}\left(|\lambda| \theta_{L 2}-A_{2} \sigma_{2}\right) \alpha^{*}}{\sigma}
$$

$$
r^{*}-p_{2}^{*}=\frac{-\theta_{L 2}\left(\lambda \mid \theta_{L 1}+A_{1} \sigma_{1}\right) \alpha^{*}}{\sigma}
$$

$$
\phi^{*}=y_{1}^{*}-K^{*}=\frac{\left[\left(C_{1} \sigma_{1}+C_{2} \sigma_{2}\right)\left(|\lambda| \theta_{L 2}-A_{2} \sigma_{2}\right)+\sigma C_{2} \sigma_{2}\right] \alpha^{*}}{|\lambda| \sigma}
$$

$$
\mathrm{y}_{2}^{*}-\mathrm{L}^{*}=-\frac{\left[\left(\mathrm{D}_{1} \sigma_{1}+\mathrm{D}_{2} \sigma_{2}\right)\left(|\lambda| \theta_{L 2}-\mathrm{A}_{2} \sigma_{2}\right)+\sigma_{2} \sigma_{2}\right] \alpha^{*}}{|\lambda| \sigma},
$$

where $A_{1}, A_{2}, C_{1}, C_{2}, D_{1}$ and $D_{2}$ are all positive and are defined in the appendix and, as before, $\sigma=\left(1+\sigma_{s}\right)|\lambda| \cdot|\theta|$. The effects of a change in $\alpha$ on real factor rewards, the rate of growth of capital and the per capita consumption in terms of the consumption good can be analyzed in terms of equations (4.1)-(4.8). Consider first the case where the momentary equilibrium is uniquely determined, so that $\sigma>0$. With $\sigma>0$, it is now the sign of $|\lambda|$ which crucially determines the behaviour of real factor rewards. If $|\lambda|<0$, which means from (2.6) that $k_{2}<k_{1}$, it is clear from (4.1) and (4.2) that a rise in $\alpha$ results in a decline in the wage rate in the first sector in terms of both commodities, and conversely. From (4.5) the real reward of capital in terms of the first commodity rises as a result of a rise in $\alpha$. However, the verdict is not so clear for the real wage rate and the reward of capital in terms of the second 
sector. The reason for this indeterminacy is not far to seek. From (2.5) we know that $\alpha^{*}+w_{1}^{*}=w_{2}^{*}$, or $\alpha^{*}+\left(w_{1}^{*}-p_{j}^{*}\right)=\left(w_{2}^{*}-p_{j}^{*}\right),(j=1,2)$. When the second sector is labor-intensive (in the physical sense), $\alpha^{*}$ and $\left(w_{1}^{*}-p_{j}^{*}\right.$ ) are negatively related, so that it is not surprising to find that $\left(w_{2}^{*}-p_{j}^{*}\right)$ may not have the same sign as $\left(w_{1}^{*}-p_{j}^{*}\right)$. The same type of explication applies to the case of real reward of capital in the second sector. Thus if $\left(w_{2}^{*}-p_{j}^{*}\right)$ does not have the same sign as $\left(w_{1}^{*}-p_{j}^{*}\right)$, then it follows from the assumption of linear homogeneity of production functions that $\left(r^{*}-p_{1}^{*}\right)$ and $\left(\mathrm{r}^{*}-\mathrm{p}_{2}^{*}\right)$ will also be opposite in sign.

When $|\lambda|>0$, that is, $k_{2}>k_{1}$, the results are reversed. Here it is the real wage rate and the reward of capital in the second sector that have a monotonic relationship with $\alpha$. When the first sector is labor-intensive, a rise (decline) in $\propto$ raises (lowers) the real wage rate in the second sector in terms of both prices, but lowers (raises) the real reward of capital in terms of the second sector. However, once again the real wage rate in the first sector and the real reward of capital in terms of the same sector may not possess a unique relationship with $\alpha$. Thus we conclude that a change in $\alpha$ affects the real wage rate unambiguously only in one sector, the effect on the real wage rate in the other sector being indeterminate. Similarly, the real reward of capital is uniquely related to $\alpha$ in terms of only one commodity price.

This discussion suggests interesting and important policy prescriptions for trade unions. To be specific, assume that the second sector is the unionized sector and $\alpha>1$, so that $w_{1}<w_{2}$. In other words, suppose that the producers in the unionized sector have to pay a premium to labor over the labor force employed in the nonunion, first sector. Suppose further that 
the union in the second sector seeks to secure an increase in this premium, thereby increasing the value of $\alpha$. However, a rise in $\alpha$ will unambiguously raise the real wage rate in the unionized sector only if this sector is capital-intensive relative to the first sector. If the unionized sector is labor-intensive, the wage rate in the union-sector may actually decline and the union action may turn out to be self defeating. This result has been recently derived by Magee (1971), Jones (1970), Johns on and Mieskowski (1970) and Batra and Pattanaik. 10 However, it has not been made clear that if the union labor suffers, the non-union labor must benefit. Furthermore, the effects on the reward of capital are indeterminate, that is to say, it is not clear just from the sign of $|\lambda|$ alone, whether the reward of capital will rise or fall in terms of both conmodity prices.

Until now we have assumed that the momentary equilibrium is uniquely determined, so that $\sigma>0$. In the presence of multiple equilibria, however, where $\sigma$ is negative for some values of $\omega_{1}$, the results derived above are reversed. Here the union labor suffers if the union sector is capital-intensive relative to the non-union sect or.

Next consider the effects of a change in $\alpha$ on the rate of growth of capital $(\phi)$. Unfortunately the results here are more muddled and perplexing than before. One glance at equation (4.7) reveals that the source of confusion lies in the sign of $\left(|\lambda| \theta_{L 2}-A_{2} \sigma_{2}\right)$ and $\sigma_{\text {. }}$ Even if we assume that $\sigma>0$, little is gained in terms of clarity, for the sign of $\left(|\lambda| \theta_{L 2}-A_{2} \sigma_{2}\right)$ is still intractable. A sufficient condition for the relationship between $\phi$ and $\alpha$ to be monotonic is that $|\lambda| \theta_{L 2}>A_{2} \sigma_{2}$, because then $|\lambda|>0$ becomes a necessary condition, so that with $\sigma>0, \phi^{*} / \alpha^{*}>0$. However, this sufficient condition does not lend itself to simple economic interpretation. Results are, of course, clear if $\sigma<0$, because then with $|\lambda|<0$, or $k_{2}<k_{1}$, 
$\phi^{*} / \alpha^{*}<0$. However, here the momentary equilibrium is not unique, and the unambiguity of the result loses most of its attraction.

Fortunately, there is one special case in which the results are crystal clear. If the elasticity of factor substitution in both sectors equals unity, the implications of a change in $\alpha$ for $\phi$ are apparent at one glance. As will be shown in the appendix, the complicated expression (4.7) reduces to

$$
\phi^{*}=\lambda_{\mathrm{L} 2} \theta_{\mathrm{L} 1} \alpha^{*}
$$

when $\sigma_{1}=\sigma_{2}=1$. In other words, a rise in $\alpha$ raises the rate of growth of capital at a given capital/labor ratio in the economy, and conversely. When $\alpha<1, w_{1}>w_{2}$, and the differential is paid by the capital-goods sector. Here a rise in $\alpha$ implies a decline in the wage differential. The role of $\alpha$ is reversed when $\alpha>1$, so that the differential is paid by the consumption-goods sector. Here a rise in a signifies a rise in the wage differential. From this discussion, the following theorem is immediate:

Theorem 3: A decline in the wage-differential paid by the capital-goods sector, or a rise in the differential paid by the consumption-goods sector results in a rise in the rate of growth of capital at any capital/labor ratio, and conversely, provided the momentary equilibrium is uniquely determined, that is, $\sigma>1$, and the production functions in both sectors are of the Cobb-Douglas type. 
It follows from theorem 3 that the overall capital/1abor ratio of the economy will be higher in the balanced growth path, the higher is the level of $\alpha$, and will be lower, the lower is the level of $\alpha$. An interesting corollary to this result is that the capital/labor ratio in the balanced growth path will be higher when $\alpha>1$ and lower when $\alpha<1$ than the capital/ labor ratio which prevails in the absence of the wage differential (when $\alpha=1$ ). A further appreciation of this result may be gained from Figure 3 which depicts a negative, monotonic relationship between $k$ and $\phi$, implying thereby that the growth model is stable. The curve $A B, A^{\prime} B^{\prime}$ and $A^{\prime \prime} B$ " have been drawn for different values of $\alpha$. Consider first the case where $\alpha>1$. A decline in $\alpha$ results in a decline in $\phi$ at any $k$, so that the curve $A^{\prime} B^{\prime}$ shifts to the left, and, in the limiting case, where $\alpha$ approaches unity, the curve $A^{\prime} B^{\prime}$ shifts to $\dot{A B}$. The balanced growth path, when $\alpha>1$, is achieved

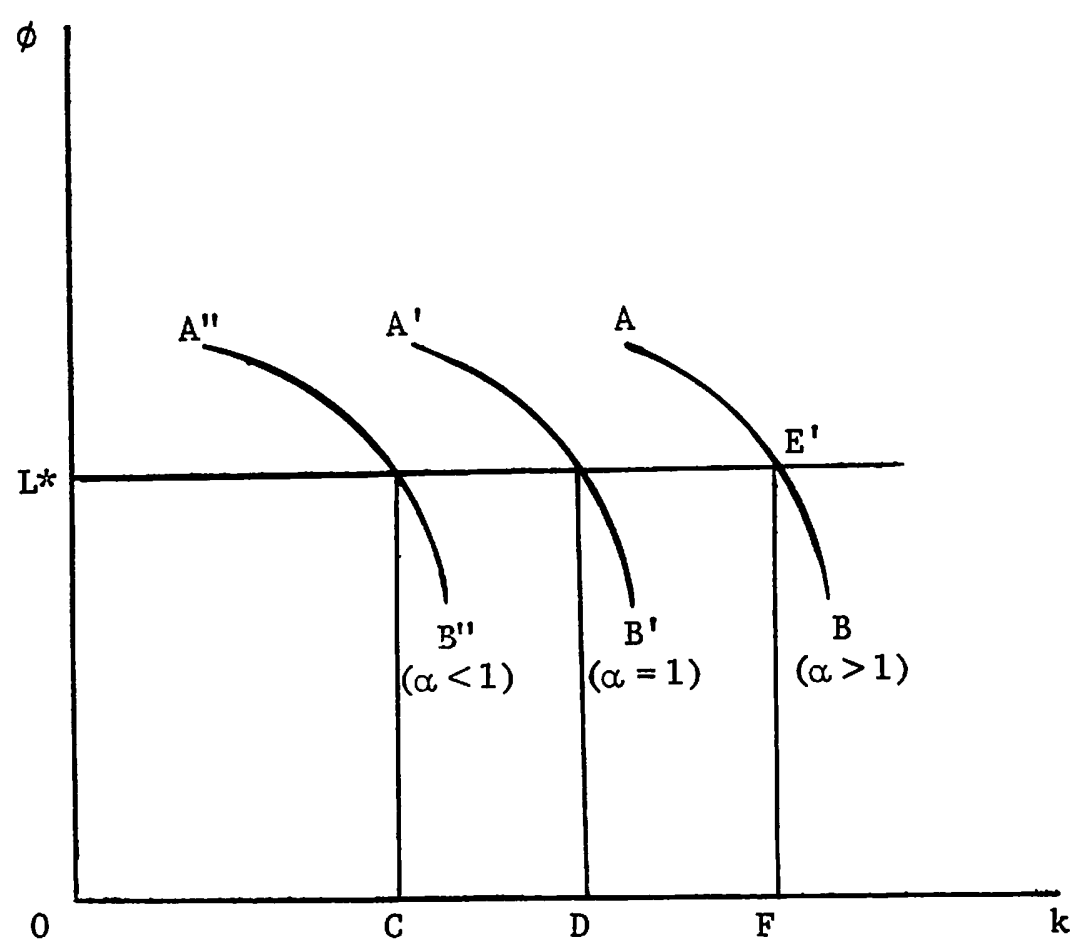


at point $E^{\prime}$ where $\phi$ equals the given rate of growth of labor (L*), and the corresponding balanced capital/labor ratio is given by $O F$. Clearly then the balanced capital/labor ratio in the absence of the wage differential equals OD. Thus, we see that the balanced $k$ for the case where $\alpha>1$ or $w_{2}>w_{1}$ is greater than the corresponding $k$ in the absence of the wage differential. In other words, the introduction of a wage differential against the consumption-goods sector results in a higher capital-intensity in the economy in the long run. Conversely, the introduction of a wage differential against the capital-goods sector leads to a lower capital-intensity $(=0 C)$ in the long run equilibrium.

The effects of a change in $\alpha$ on the per capita consumption are symmetrical, though opposite, to those on the rate of growth of capital. Equation (4.8) is as tedious to interpret as its predecessor, equation (4.7). However, with $\sigma_{1}=\sigma_{2},(4.8)$ simplifies to

$$
\mathrm{y}_{2}^{*}-\mathrm{L}^{*}=-\lambda_{\mathrm{L} 1^{\theta}} \mathrm{I}_{2}{ }^{*}
$$

From (4.10), it is evident that a rise in $\alpha$ results in a lower per capita consumption, and a decline in $\alpha$ leads to a rise in per capita consumption. In other words, a higher value of $\alpha$ is associated not only with a higher capitalintensity in the economy but also with a lower per capita consumption,and vice versa.

\section{Conclusions}

Although the intersectoral factor-price differentials are a certain fact of life, their implications have been until now explored only in terms of the static two-sector, two-factor model. The foregoing analysis, however, has been concerned with the analysis of factor market distortions in terms of a two-sector growth model. The main conclusions of this study may be summarized as follows: 
1. With a constant propensity to save, the momentary equilibrium in the traditional two-sector growth model, where factor market imperfections have been ignored, is uniquely determined. However, in the presence of the wage differential, this result is valid only if the intersectoral factorintensity relations are the same in both the physical and the value sense. Otherwise, there arises a strong possibility of multiple equilibria.

2. Traditionally it has been shown that the two-sector growth model is stable if the capital-intensity condition is satisfied. In the presence of the factor-price differential, this condition comes to acquire a different role and meaning. Now a distinction has to be drawn between the capitalintensity condition in the physical and the value sense, and there is no a priori reason to ensure that their signs are the same. Specifically, we have shown that the two-sector growth model may be unstable if the capitalintensity condition is satisfied in the physical sense but not in the value sense. It is only when the consumption-goods sector is capital-intensive relative to the capital-goods sector in both "senses", that the growth model can be unambiguously said to be stable for any given level of the intersector factor-price differential.

3. As far as the elasticity condition for stability is concerned, here again our results do not conform to the conventional discussions. Even if the elasticity of factor substitution equals or exceeds unity in each sector, the growth model in the presence of the differential may be unstable. 4. Another interesting result is that although the long run equilibrium may be uniquely determined in spite of the differential, the momentary equilibrium may not. This is a complete antithesis to the customary results. 
5. Assuming that the long run equilibrium is uniquely determined, the effects of a change in the factor-price differential were explored for factor rewards, the rate of growth of capital and the per capita consumption. It was shown that a rise in the wage differential paid by the consumption-goods sector or a decline in the one paid by the capital-goods sector results in a rise in the rate of growth of capital and a decline in the per capita consumption at any capital/labor ratio, provided the production functions are of the Cobb-Douglas variety. An interesting corollary to this result is that in the balanced growth path, the economy's capital/labor ratio is higher when the wage differential is paid by the consumption-goods sector and lower when it is paid by the capital-goods sector than the overall capital/labor ratio which would prevail if the wage differential did not exist. 


\section{Footnotes}

1. For an extensive bibliography of literature on two-sector growth models, see Burmeister and Dobell (1970). Among the recent articles written on this subject are those of Batra (1970), Batra and Singh (1970), Stiglitz (1969) and Chang (1970).

2. A further proximity to reality could, of course, be achieved by introducing conditions of imperfect competition in product markets. This, however, constitutes subject matter for another paper and has been recently analyzed by Batra (1971).

3. The nature of our analysis in section IV is comparative-dynamic, rather than comparative-statics, which has been the method of analysis in numerous published and unpublished articles. See, for example, Batra and Pattanaik (1970), Batra and Scully (1971), Magee (1971), Bhagwati and Srinivasan (1971), Herberg and Kemp (1969) and Jones (1970).

4. For further details on the elasticity of the transformation curve, see Jones (1965, 1961).

5. When $\alpha$ is constant, $w_{1}^{*}$ and $w_{2}^{*}$ are equal. Therefore, in order to obtain a relationship between $k$ and the wage/rental ratio in both sectors, it is enough to derive the relationship between $k$ and $\omega_{1}$ only, the one between $k$ and $\omega_{2}$ following the same direction. This is the line of approach which will be followed in this section and the next.

6. For further details on this point, see Magee (1971), Herberg, Kemp and Magee (1970) and Jones (1970).

7. One may wonder why the momentary equilibrium is not uniquely determined when $k^{*}$ and $\omega_{1}^{*}$ are negatively related even though this relationship under some conditions is unique. However, for the reason cited in the text, $k$ and $\omega_{1}$ cannot be negatively related for all values of $w_{1}$. For example if $w_{1}$ rises, $k_{2}$ and $k_{1}$ will both rise, but $k$, which is a weighted average of $k_{2}$ and $k_{1}$ (the weights being the proportion of labor employed in each sector), may still decline if the weights change in a certain manner. However, this cannot go on indefinitely. If $w_{1}$ (or $w_{2}$ ) approaches infinity, both $k_{2}$ and $k_{1}$ approach infinity, so that $k$ must also approach infinity, no matter what way the weights change. Thus the negative relationship between $k$ and $\omega_{1}$ is not compatible with all levels of $\omega_{1}$, although the positive relationship is. Hence with $k^{*} / \omega_{1}<0$, the momentary equilibrium cannot be unique for all levels of $\omega_{1}$.

8. See equation (2.22) and the results derived from it in the last section.

9. See the remarks made in footnote 3 above.

10. See Batra and Pattanaik (forthcoming). 


\section{Mathematical Appendix}

In what follows, the derivation of equations $(4.1)$ to $(4.10)$ is shown. It will be remembered that we are assuming $\mathrm{K}^{*}=\mathrm{L}^{*}$. Furthermore, the following definitions and relationships are used:

$$
\begin{aligned}
& \beta_{\mathrm{L}}=\lambda_{\mathrm{L} 1} \theta_{\mathrm{K} 1} \sigma_{1}+\lambda_{\mathrm{L} 2} \theta_{\mathrm{K} 2} \sigma_{2} \\
& \beta_{\mathrm{K}}=\lambda_{\mathrm{K} 1} \theta_{\mathrm{L} 1} \sigma_{1}+\lambda_{\mathrm{K} 2} \theta_{\mathrm{L} 2} \sigma_{2} \\
& \mathrm{~A}_{1}=\lambda_{\mathrm{L} 1} \theta_{\mathrm{K} 1}+\lambda_{\mathrm{K} 1} \theta_{\mathrm{L} 1} \\
& \mathrm{~A}_{2}=\lambda_{\mathrm{L} 2} \theta_{\mathrm{K} 2}+\lambda_{\mathrm{K} 2} \theta_{\mathrm{L} 2} \\
& \mathrm{C}_{1}=\lambda_{\mathrm{L} 1} \lambda_{\mathrm{K} 2} \theta_{\mathrm{K} 1}+\lambda_{\mathrm{L} 2} \lambda_{\mathrm{K} 1} \theta_{\mathrm{L} 1} \\
& \mathrm{C}_{2}=\lambda_{\mathrm{L} 2} \lambda_{\mathrm{K} 2} \\
& \mathrm{D}_{1}=\lambda_{\mathrm{L} 1} \lambda_{\mathrm{K} 1} \\
& \mathrm{D}_{2}=\lambda_{\mathrm{L} 2} \lambda_{\mathrm{K} 1} \theta_{\mathrm{K} 2}+\lambda_{\mathrm{L} 1} \lambda_{\mathrm{K} 2} \theta_{\mathrm{L} 2} \\
& \beta_{\mathrm{L}}+\beta_{\mathrm{K}}=\mathrm{A}_{1} \sigma_{1}+\mathrm{A}_{2} \sigma_{2} \\
& \sigma=\beta_{\mathrm{L}}+\beta_{\mathrm{K}}+|\lambda| \cdot|\theta|=\mathrm{A}_{1} \sigma_{1}+\mathrm{A}_{2} \sigma_{2}+|\lambda| \cdot|\theta| \\
& \mathrm{A}_{1}+\mathrm{A}_{2}=\left(|\lambda| \theta_{\mathrm{K} 1}+\lambda_{\mathrm{K} 1}\right)\left(\lambda_{\mathrm{K} 2}-|\lambda| \theta_{\mathrm{K} 2}\right)=1-|\lambda| \cdot|\theta| \\
& \lambda_{\mathrm{K} 2 \beta_{\mathrm{L}}}+\lambda_{\mathrm{L} 2} \beta_{\mathrm{K}}=\mathrm{C}_{1} \sigma_{1}+\mathrm{C}_{2} \sigma_{2} \\
& \lambda_{\mathrm{K} 1} \beta_{\mathrm{L}}+\lambda_{\mathrm{L} 1} \beta_{\mathrm{K}}=\mathrm{D}_{1} \sigma_{1}+\mathrm{D}_{2} \sigma_{2}
\end{aligned}
$$

From $(2.17)$ and $(2.18)$ we have

$$
\left(y_{1}^{*}-y_{2}^{*}\right)=\left(\beta_{L}+\beta_{K}\right) \frac{\left(w_{1}^{*}-r^{*}\right)}{|\lambda|}+\frac{A_{2} \sigma_{2}}{|\lambda|} \alpha^{*}
$$

On the other hand, from (2.9) and (2.10) 
(A.2) $\left(w_{1}^{*}-r^{*}\right)=\frac{\left(p_{1}^{*}-p_{2}^{*}\right)}{|\theta|}+\frac{\theta_{L 2}}{|\theta|} \alpha^{*}$

Substituting (A.2) into (A.1), and using (2.20), we obtain

(A.3)

$$
\left(w_{1}^{*}-r^{*}\right)=\frac{\left(|\lambda| \theta_{L 2}-A_{2} \sigma_{2}\right) \alpha^{*}}{\sigma}
$$

and

(A.4)

$$
\begin{aligned}
\left(p_{1}^{*}-p_{2}^{*}\right) & =-\frac{\left(\theta_{L 2} A_{1} \sigma_{1}+\theta_{L 1} A_{2} \sigma_{2}\right)}{\sigma} \alpha^{*} \\
& =\left\{\frac{\left(|\lambda| \theta_{L 2}-A_{2} \sigma_{2}\right)|\theta|}{\sigma}-\theta_{L 2}\right\} \alpha^{*}
\end{aligned}
$$

Returning to $(2.9)$ and $(2.10)$, we may derive

(A.5)

$$
\left(w_{1}^{*}-p_{1}^{*}\right)=\frac{\theta_{K 1}}{|\theta|}\left(p_{1}^{*}-p_{2}^{*}\right)+\frac{\theta_{L 2} \theta_{K 1}}{|\theta|} \alpha^{*}
$$

(A.6)

$$
\left(r^{*}-p_{1}^{*}\right)=-\frac{\theta_{L 1}}{|\theta|}\left(p_{1}^{*}-p_{2}^{*}\right)-\frac{\theta_{L 1} \theta_{L 2}}{|\theta|} \alpha^{*}
$$

Substituting for $\left(p_{1}^{*}-p_{2}^{*}\right)$ from (A.4), we get

(A. 7)

$$
\begin{aligned}
\left(\mathrm{w}_{1}^{*}-\mathrm{p}_{1}^{*}\right) & =\frac{\theta_{\mathrm{K} 1}}{|\theta|}\left\{\theta_{\mathrm{L} 2}-\frac{\left(\theta_{\left.\mathrm{L} 2 \mathrm{~A}_{1} \sigma_{1}+\theta_{\mathrm{L} 1} \mathrm{~A}_{2} \sigma_{2}\right)}^{\sigma}\right\} \alpha^{*}}{}=\frac{\theta_{\mathrm{K} 1}\left(|\lambda| \theta_{\mathrm{L} 2}-\mathrm{A}_{2} \sigma_{2}\right)}{\sigma} \alpha^{*}\right.
\end{aligned}
$$

$(\mathrm{A} .8)$

$$
\begin{aligned}
\left(r-p_{1}^{*}\right) & =-\frac{\theta_{L 1}}{|\theta|}\left\{\theta_{L 2}-\frac{\left(\theta_{L 2} A_{1} \sigma_{1}+\theta_{L 1} A_{2} \sigma_{2}\right)}{\sigma}\right\} \alpha^{*} \\
& =\frac{-\theta_{L 1}\left(|\lambda| \theta_{L 2}-A_{2} \sigma_{2}\right)}{\sigma} \alpha^{*}
\end{aligned}
$$


From (A.4) and (A.5)

(A.9)

$$
\begin{aligned}
\left(w_{1}^{*}-p_{2}^{*}\right) & =\frac{\theta_{K 2}}{T_{1}}\left(p_{1}^{*}-p_{2}^{*}\right)+\frac{\theta_{L 2} \theta_{K 1}}{|\theta|} \alpha^{*} \\
& \left.=\frac{\left\{\theta_{K 2}\left(|\lambda| \theta_{L 2}-A_{2} \sigma_{2}\right)\right.}{\sigma}-\theta_{L 2}\right\} \alpha^{*} \\
& =\frac{\left(|\lambda| \theta_{K 1} \theta_{L 2}-\theta_{L 2} A_{1} \sigma_{1}-A_{2} \sigma_{2}\right)}{\sigma} \alpha^{*}
\end{aligned}
$$

Similarly, from (A.4) and (A.6)

(A.10)

$$
\begin{aligned}
\left(r^{*}-p_{2}^{*}\right) & =-\frac{\theta_{L 2}}{|\theta|}\left(p_{1}^{*}-p_{2}^{*}\right)-\frac{\theta_{L 1} \theta_{L 2}}{|\theta|} \alpha^{*} \\
& =\frac{-\theta_{L 2}\left(|\lambda| \theta_{L 1}+A_{1} \sigma_{1}\right)}{\sigma} \alpha^{*}
\end{aligned}
$$

Adding $\alpha^{*}$ to both sides of (A.7):

(A.11)

$$
\begin{aligned}
\alpha^{*}+\left(w_{1}^{*}-p_{1}^{*}\right) & =\left(w_{2}^{*}-p_{1}^{*}\right)=\left\{\frac{\theta_{\mathrm{K} 1}\left(|\lambda| \theta_{L 2}-A_{2} \sigma_{2}\right)}{\sigma}+1\right\} \alpha^{*} \\
& =\frac{\left(|\lambda| \theta_{\mathrm{K} 2} \theta_{L 1}+A_{1} \sigma_{1}+\theta_{L 1} A_{2} \sigma_{2}\right)}{\sigma} \alpha^{*}
\end{aligned}
$$

Similar1y, from (A.9):

(A.12)

$$
\begin{aligned}
\left(w_{2}^{*}-p_{2}^{*}\right) & =\left\{\frac{\left(|\lambda| \theta_{\mathrm{K} 1} \theta_{L 2}-\theta_{L 2} A_{1} \sigma_{1}-A_{2} \sigma_{2}\right)}{\sigma}+1\right\} \alpha^{*} \\
& =\frac{\theta_{K 2}\left(|\lambda| \theta_{L 1}+A_{1} \sigma_{1}\right)}{\sigma} \alpha^{*}
\end{aligned}
$$

The change in the rate of growth of capital is derived from $(2.17)$ and (2.18): 


$$
\begin{aligned}
& \phi^{*}=\left(y_{1}^{*}-K^{*}\right)=\frac{\lambda_{K 2}}{|\lambda|}\left[L^{*}+\beta_{L}\left(w_{1}^{*}-r^{*}\right)+\lambda_{L 2} \theta_{K 2} \sigma_{2} \alpha^{*}\right] \\
& -\frac{\lambda_{L 2}}{|\lambda|}\left[K^{*}-\beta_{K}\left(w_{1}^{*}-r^{*}\right)-\lambda_{K 2} \theta_{L 2} \sigma_{2} \alpha^{*}\right]-K^{*} \\
& =\left(\lambda_{\mathrm{K} 2}{ }^{\beta} \mathrm{L}+\lambda_{\mathrm{L} 2} \beta_{\mathrm{K}}\right) \frac{\left(w_{1}^{*}-\mathrm{r}^{*}\right)}{|\lambda|}+\frac{\lambda_{\mathrm{L} 2} \lambda_{\mathrm{K} 2} \sigma_{2}}{|\lambda|} \alpha^{*} \\
& =\left(c_{1} \sigma_{1}+C_{2} \sigma_{2}\right) \frac{\left(w_{1}^{*}-r^{*}\right)}{|\lambda|}+\frac{c_{2} \sigma_{2}}{|\lambda|} \alpha^{*} .
\end{aligned}
$$

Substituting from (A.3):

$$
\phi^{*}=\frac{\left[\left(\mathrm{C}_{1} \sigma_{1}+\mathrm{C}_{2} \sigma_{2}\right)\left(|\lambda| \theta_{L 2}-\mathrm{A}_{2} \sigma_{2}\right)+\sigma_{2} \sigma_{2}\right] \alpha^{*}}{|\lambda|^{\sigma}}
$$

Similarly, the change in the rate of growth of consumption per capita is given by

$$
\begin{aligned}
& \left(y_{2}^{*}-L^{*}\right)=-\frac{\lambda_{\mathrm{K} 1}}{|\lambda|}\left[L^{*}+\beta_{L}\left(w_{1}^{*}-r^{*}\right)+\lambda_{L 2} \theta_{K 2} \sigma_{2} \alpha^{*}\right] \\
& +\frac{\lambda_{\mathrm{L} 1}}{|\lambda|}\left[\mathrm{K}^{*}-\beta_{\mathrm{K}}\left(\mathrm{w}_{1}^{*}-\mathrm{r}^{*}\right)-\lambda_{\mathrm{K} 2} \theta_{\mathrm{L} 2} \sigma_{2} \alpha^{*}\right]-\mathrm{L}^{*} \\
& =-\left(\lambda_{\mathrm{K} 1} \beta_{\mathrm{L}}+\lambda_{\mathrm{L} 1} \beta_{\mathrm{K}}\right) \frac{\left(\mathrm{w}_{1}^{*}-\mathrm{r}^{*}\right)}{|\lambda|}-\frac{\left(\lambda_{\mathrm{K} 1} \lambda_{\mathrm{L} 2} \theta_{\mathrm{K} 2}+\lambda_{\mathrm{L} 1} \lambda_{\mathrm{K} 2} \theta_{\mathrm{L} 2}\right)}{|\lambda|} \sigma_{2} \alpha^{*} \\
& =-\left(\mathrm{D}_{1} \sigma_{1}+\mathrm{D}_{2} \sigma_{2}\right) \frac{\left(\mathrm{w}_{1}^{*}-\mathrm{r}^{*}\right)}{|\lambda|}-\frac{\mathrm{D}_{2} \sigma_{2}}{|\lambda|} \alpha^{*} \\
& =\frac{-\left[\left(\mathrm{D}_{1} \sigma_{1}+\mathrm{D}_{2} \sigma_{2}\right)\left(|\lambda| \theta_{\mathrm{L} 2}-\mathrm{A}_{2} \sigma_{2}\right)+\sigma_{2} \sigma_{2}\right]}{|\lambda| \sigma} \alpha^{*}
\end{aligned}
$$


For the special case where $\sigma_{1}=\sigma_{2}=1,($ A.13) and (A.14) may be simplified by noting that

$$
\sigma=A_{1}+A_{2}+|\lambda| \cdot|\theta|=1
$$

and

$$
\left(|\lambda| \theta_{\mathrm{L} 2}-\mathrm{A}_{2} \sigma_{2}\right)=\left(\lambda_{\mathrm{K} 2}-\lambda_{\mathrm{L} 2}\right) \theta_{\mathrm{L} 2}-\left(\lambda_{\mathrm{L} 2} \theta_{\mathrm{K} 2}+\lambda_{\mathrm{K} 2} \theta_{\mathrm{L} 2}\right)=\lambda_{\mathrm{L} 2}
$$

Hence

$$
\begin{aligned}
\phi^{*} & =\frac{\left[\left(c_{1}+c_{2}\right)\left(-\lambda_{L 2}\right)+c_{2}\right] \alpha^{*}}{|\lambda|} \\
& =\frac{\left(-\lambda_{L 2} C_{1}+\lambda_{L 1} c_{2}\right) \alpha^{*}}{|\lambda|}=\lambda_{L 2} \theta_{L 1} \alpha^{*}
\end{aligned}
$$

and

$$
\begin{aligned}
\left(y_{2}^{*}-L^{*}\right) & =\frac{-\left[\left(D_{1}+D_{2}\right)\left(-\lambda_{L 2}\right)+D_{2}\right] \alpha^{*}}{|\lambda|} \\
& =\frac{\left(\lambda_{L 2} D_{1}-\lambda_{L 1} D_{2}\right) \alpha^{*}}{|\lambda|}=-\lambda_{L 1} \theta_{L 2} \alpha^{*}
\end{aligned}
$$




\section{$\underline{\text { References }}$}

Batra, R. N. (1969). "Activity Analysis and the Pure Theory of International Trade," American Economist (Spring, 1969).

(1970). "Hicks and Harrod Neutral Technical Progress and Stability in a Two-Sector Model of Economic Growth," Journal of Political Economy (January/February, 1970).

(1971). "Monopoly Theory in General Equilibrium and the Two-Sector Mode1 of Economic Growth," Discussion Paper, University of Western Ontario (January, 1971).

Batra, R. N., and P. K. Pattanaik (1970). "Domestic Distortions and the Gains from Trade," Economic Journal (September, 1970).

- "Factor Market Imperfections, the Terms of Trade, and Welfare," forthcoming in the American Economic Review.

Batra, R. N., and G. W. Scully (1971). "The Theory of Wage Differentials: Welfare and Immiserizing Growth," Journal of International Economics (June, 1971).

Batra, R. N., and R. Singh (1970). "Intermediate Products and the Two-Sector Growth Model," Paper Presented at the Econometric Society Meetings, Detroit (December, 1970).

Bhagwati, J., and V. K. Ramaswami (1963). "Domestic Distortions and the Theory of Optimum Subsidy," Journal of Political Economy (February, 1963).

Bhagwati, J., and T. N. Srinivasan (1971). "The Theory of Wage Differentials: Production Response and Factor Price Equalisation," Journal of International Economics (February, 1971).

Burmeister, E., and A. R. Dobell (1970). Mathematical Theories of Economic Growth (Lond on: The Macmillan Company, 1970).

Chang, W. W. (1970). "Induced Bias in Invention and Two-Sector Growth Models," Paper Presented at the Econometric Society Meetings, Detroit (December, 1970).

Harberger, A. C. (1962). "The Incidence of the Corporation Income Tax," Journal of Political Economy (June, 1962).

Herberg, H., M. C. Kemp, and S. P. Magee (1970). "Factor Market Distortions, The Reversal of Relative Factor Intensities, and the Relation Between Product Prices and Equilibrium Output," Mimeographed (1970).

Inada, K. (1964). "On the Stability of Growth Equilibria in Two-Sector Models," Review of Economic Studies (April, 1964). 
Johnson, H. G. (1966). "Factor Market Distortions and the Shape of the Transformation Curve," Econometrica (July, 1966).

Johnson, H. G., and P. Mieszkowski (1970). "The Effects of Unionization on the Distribution of Income: A General Equilibrium Approach," Quarterly Journal of Economics (November, 1970).

Jones, R. W. (1961). "Stability Conditions in International Trade: A General Equilibrium Analysis," International Economic Review (May, 1961).

(1965). "The Structure of Simple General Equilibrium Models," Journal of Political Economy (December, 1965).

(1970). "Distortions in Factor Markets and the General Equilibrium Mode1 of Production," Mimeographed (1970).

Kemp, M. C., and H. Herberg (1969). "Factor Market Distortions, the Shape of the Locus of Competitive Outputs, and the Relation Between Product Prices and Equilibrium Outputs," Discussion Paper, University of Southampton (August, 1969).

Magee, S. P. (1971). "Factor Market Distortions, Production, Distribution and the Pure Theory of International Trade," Quarterly Journal of Economics (August, 1971).

Shinkai, Y. (1960). "On Equilibrium Growth of Capital and Labor," International Economic Review (May, 1960).

Stiglitz, J. E. (1969). "Allocation of Heterogeneous Capital Goods in a Two-Sector Economy," International Economic Review (October, 1969).

Uzawa, H. (1961). "On a Two-Sector Model of Economic Growth," Review of Economic Studies (October, 1961). 